\title{
MODEL NATIVIS LANGUAGE ACQUISITION DEVICE (SEBUAH TEORI PEMEROLEHAN BAHASA)
}

\author{
Mamluatul Hasanah \\ Dosen Jurusan Bahasa dan Sastra Arab, \\ Fakultas Humaniora dan Budaya, Universitas Islam Negeri (UIN) Malang. \\ Jalan Gajayana No. 50 Telepon (0341) 570872, Faksimile (0341) 570872 Malang 65144
}

\begin{abstract}
The ability of using mother tongue has been possessed by every child. They can master the language without getting specific education. In a short time a child has mastered the language to communicate with others. There are many theories of language acquisition. One of them that still exists is The Native Model of Language Acquisition (LAD). This theory was pioneered by Noam Chomsky. In this language naturally. This ability develops automatically when the language is used is Language Acquisition Device (LAD). LAD constitutes a hypothesis of feature of grammatical rules used progressively by a child in accordance with his psychological development.
\end{abstract}

\section{Key words}

Language Acquisition Device (LAD), Chomsky, Children

\section{Pendahuluan}

Di dalam khazanah pustaka psikolinguistik, teori pemerolehan bahasa (selanjutnya disebut TPB) dapat dikelompokkan menjadi empat rumpun. Yaitu (1) rumpun behavioris, (2) rumpun kognitif, (3) rumpun nativis, dan (4) rumpun humanistis (Brown dalam Saryono 1992 : 1).

Masing-masing rumpun TPB mengembangkan berbagai model pemerolehan bahasa yang mencerminkan landasan filsafat yang 
mempengaruhinya. Rumpun behavioris memunculkan 7 model TPB, rumpun kognitif melahirkan 6 model TPB, rumpun nativis dengan 7 model TPB, dan rumpun humanistis memunculkan 4 TPB.

Model-model TPB rumpun behavioris berlandaskan filsafat empiris, psikologi behavioris, dan linguistik struktural Amerika. Modelmodel rumpun kognitif dilandasi oleh filasafat rasionalis Descartes dan pasca Descartes serta psikologi kognitif Gestalt. Model-model TPB rumpun nativis lebih berlandasakn rasionalis kritis pasca Descartes, khususnya rasionalisme kritis Immanuel Kant, di samping berlandaskan model TPB nativis LAD yang ditemukan oleh Chomsky. Model-model TPB rumpun humanistis berlandaskan sosiolinguistik, psikologis humanistis, dan filsafat eksistensial dan fenomenologis (Koeswra, 1986 : 112-114).

Namun demikian, tidak semua model dari keempat rumpun TPB yang dikemukakan di atas mendominasi pengkajian pemerolehan bahasa dan pengajaran bahasa. Sejauh pemgamatan penulis hanya ada empat model yang paling mendominasi pengkajian pemerolehan dan pengajaran bahasa yaitu (1) TPB model pengondisian operan dari rumpun behavioris, (2) TPB model pengembangan intelektual dari rumpun kognitif, TPB model nativis LAD dari rumpun nativis dan (4) TPB model komunikatif dari rumpun humanistis.

Tulisan ini mengemukakan tentang TPB model nativis Language Acquisition Device (selanjutnya disebut TPB nativis LAD) yang mencakup: 1) latar belakang munculnya TPB Model Nativis, 2) Landasan TPB Model Nativis LAD, 3) Pandangan-pandangan TPB Model Nativis LAD, dan 4) Kritik-kritik Terhadap TPB Model Nativis LAD.

\section{Latar Belakang TPB Model Nativis LAD}

Penelitian tentang pemerolehan Bahasa anak telah menarik para psikolog dan ahli bahasa. Peranan bahasa dalam hubungannya dengan perkembangan anak dan kemampuan berpikirnya sudah lama menjadi perhatian utama psikologi. Namun asumsi, teknik, dan temuan linguistik modern telah memberikan sumbangan tentang penjelasan 
dan pemecahan masalah yang ditemui di bidang itu. Oleh karena itu dapat dikatakan bahwa kajian pemerolehan bahasa maerupakan hasil pandangan psikologi dan linguistik. Sumbangan linguistik memeng belum lama, tetapi sumbangan itu cukup berharga. Sumabngaan itu mencakup bidang teoritis, metodologis dan empiris. Dari ketiga sumbangan itu, sumbangan teoritis tampak paling menonjol.

Sejak behaviorisme dan TPB (Teori Pemerolehan Bahasa) Model Pengondisian Operan mendapatkan kritik dan sanggahan, muncullah pandangan baru mengenai pemerolehan bahasa. Pandangan baru itu dilandasi oleh pikiran-pikiran rasionalis. Sejalan dengan pandangan rasionalis ini, muncul pula usaha-usaha membangun TPB baru (sebagai alternatif TPB Model Pengondisian Operan) berdasarkan pikiran-pikiran rasionalis. Dalam kaitan ini peranan Chomskylah yang telah mengubah pandangan tentang pemerolehan bahasa dan yang merintis munculnya TPB baru yang rasionalis, yaitu TPB Model Nativis LAD.

Sehubungan dengan itu, Chomsky dapat dianggap pencetus dan pengemuka TPB Nativis LAD sebab TPB model ini konstruknya dikemukakan olehnya. Secara embrional sesungguhnya model ini sudah nampak pada kritik-kritik Chomsky terhadap TPB Model Pongondisian Operan yang tertuang dalam A Review of B.F. Skinner Verbal Behavior (1959). Model ini terformulasikan secara jelas dan utuh konstruksnya pada waktu Chomsky menerbitkan Aspect of the Theory of Syntax pada tahun 1965. Dalam Aspect inilah Chomsky mengemukakan pandangan dan prinsip dasar TPB Model Nativis LAD. Model ini terus dikembangkan sebagaimana nampak pada buku-buku Chomsky berikutnya, yaitu Language and Mind (1968), Reflection on Language (1975), Language and Responsibility (1977), dan beberapa tulisan lainnya.

\section{Landasan TPB Model Nativis}

TPB Model Nativis LAD ini ditopang secara kuat oleh linguistik generatif transformasi dan filsafat rasionalisme Descartes (Tarigan, 1985:139). Kedua disiplin ini melandasi secara kukuh TPB Model Nativis LAD . 
Sebagaimana diketahui, linguistik generatif transformasi dikemukakan juga oleh Chomsky. linguistik generatif ini meyakini bahwa bahasa merupakan cermin pikir dan hasil kecendekiaan manusia yang selalu dihasilkan secara baru oleh setiap individu dengan operasioperasi yang mengatasi jangkauan keinginan dan kesadaran manusia (Chomsky, 1975:4). Bahasa dianggap sebagai sesuatu yang diciptakan oleh kedinamisan dan kemampuan organisme manusia yang menitikberatkan kemampuan kreatifnya (Samsuri, 1973:10-11). Dengan demikian, dalam linguistik generatif transformasi matra kreatif bahasa dan kekreatifan manusia sangat diperhatikan. Diperhatikan pula bahasa tulis dan lisan, matra-matra universal dan individula bahasa, dan operasi-operasi bahasa (Samsuri, 1973:10-11).

Chomsky dan ahli bahasa lain menentang paham behavioristik mengenai perolehan bahasa dengan dua argumen sebagai landasan (Bambang, 1995 : 275). Dua argumen itu adalah :

Pertama, apabila peniruan merupakan prinsip yang menentukan perolehan bahasa anak, maka kita dapat berharap bahwa anak mampu menghasilkan pola-pola bahasa yang agak berbeda dari pola bahasa yang pada kenyataannya dia hasilkan. Apabila peniruan merupakan prinsip yang menentukan, maka kita dapat berharap bahawa anak akan membuat kekeliruan dalam unsur gramatika, dan apabila ujarannya dibetulkan oleh orang yang mengasuhnya, maka segera saja dia memakai ujaran sebagaimana yang dipakai orang tuanya. Ilustrasi dari pernyataan ini dapat digambarkan sebagai berikut; seorang anak belum bisa menggunakan sebuah pola, meskipun dia diberitahu pola yang benar selama beberapa kali. Misalnya seorang anak mengatakan " tidak duduk sini" untuk melarang orang duduk di sutau tempat.Ibunya membetulkan dengan mengatakan, "jangan duduk di sini". Pada kenyataannya anak tersebut masih mangabaikan pembetulan ibunya.Meskipun sudah diingatkan berkali-kali dia tetap mengatakan "tidak duduk sini". Kesimpulan yang dapat ditarik dari contoh ini adalah anak belum mencapai tahap penggunaan pola larangan sebagaimana yang diharapkan. Dengan kata lain, pemerolehan bahasa lebih merupkan pematangan gramatika batin anak dari pada peniruan. 
Kedua, apabila peniruan merupakan prinsip yang menentukan pemerolehan bahasa anak, kita dapat berharap bahwa anak-anak tidak menghasilkan pola-pola yang pada kenyataannya mereka hasilkan. Apabila peniruan saja sudah cukup, tentunya kita tidak dapat menjelaskan sebagaian pola yang dipakai anak dalam ujaran mereka. Misalnya anak yang mengatakan menyapu dengan mesapu, metabrak dan sebagainya, bukan merupakan hasil tiruan dari orang dewasa di sekitarnya. Kasus ini menunjukkan bahwa anak berperan secara cerdik, deduktif dan kreatif dalam menyikapi bahasanya. Pemerolehan bahasa tidak sekedar hasil peniruan.

Dalam pada itu, filsafat rasionalisme Descrates menekankan rasio atau akal budi manusia. Ajarannya yang paling penting ialah kesangsian metodis, gagasan-gagasan kodrati atau bawaan, dan substansi (Pardja, 1987:6-10). Manusia dipandang sebagai makhluk dualistis. Manusia terdiri atas dua substansi, yaitu jiwa dan tubuh. Jiwa adalah pemikiran dan tubuh adalah keluasan. Dengan demikian, tubuh sekedar mesin yang dijalankan oleh jiwa (bandingkan dengan pendapat empirisme Lockel) (Pradja, 1987:10).

Pandangan-pandangan inilah yang melandasi pandanganpandangan konseptual TPB Model Nativis LAD. Jadi, dapat dikatakan bahwa pandangan-pandangan konseptual (baik yang menyangkut manusia selaku si belajar maupun proses pemerolehan bahasa) TPB Model Nativis LAD diilhami sekaligus ditransformasikan dari pandangan-pandangan konseptual linguistik transformasi dan filsafat rasionalisme Descartes.

\section{Pandangan-pandangan TPB Model Nativis}

TPB Model Nativis LAD menekankan spekulasi rasionalis tentang proses mental yang dialami oleh si belajar sewaktu belajar bahasa. Si belajar sebagai manusia dipandang selalu aktif dan kreatif. Jiwa manusia selaku si belajar selalu aktif dan kreatif mengolah masukan-masukan bahasa yang diterimanya. Keaktifan dan kekreatifan ini tidak bergantung pada adanya stimulus atau peneguhan yang 
berasal dari faktor eksternal lingkungan terutama orang tua. Keaktifan dan kekreatifan terjadi karena struktur kejiwaan memang bersubstansi demikian.

Di dalam struktur kejiwaan manusia terdapat sebuah piranti yang mengurusi pemerolehan bahasa. Menurut TPB Model Nativis LAD, setiap manusia normal yang dilahirkan ke dunia sudah diperlengkapi dengan sebuah piranti pemerolehan bahasa. piranti itu lazim disebut LAD (Language Acquisition Device) atau LAS (Language Asquisition System) (Chomsky, 1965:55). Dalam bahasa Indonesia dapat disebut PPB (Piranti Pemerolehan Bahasa) atau SPB (System Pemerolehan Bahasa). Jadi manusia lahir membawa LAD, bukan bahasa tertentu; manusia lahir membawa kemampuan kodrati untuk melakukan pemerolehan bahasa, bukan kosong sama sekali (Baradja, 1986:7). Tanpa adanya LAD mustahil seseorang dapat menguasai bahasa pertama dalam waktu relatif singkat dan menguasai sistem bahasa yang demikian rumit dan abstrak keberadaannya.

Adanya LAD dalam struktur kejiwaan manusia sebagaimana diyakini oleh TPB Model Nativis LAD didukung oleh bukti-bukti neurobiologis atau kajian neurolinguistik yang dikerjakan oleh TPB Model Neurobiologis. Dalam struktur anatomis manusia ternyata juga terdapat bagian-bagian otak dan saraf-saraf tertentu yang mengurusi bahasa. Berdasarkan kajian neurobiologis ditemukan bahwa hemisfer serebral kiri otak manusia bertugas mengurusi bahasa. Di dalam hemisfer serebral kiri ini terdapat daerah broca, daerah wernicke, daerah korteks superior atau kortikal motoris, daerah rolando, sistem sentersefalis, daerah auditoris utama, dan daerah visual utama. Daerahdaerah ini beserta saraf-saraf yang menghubungkannya menjadi sebuah struktur anatomis otak sepenuhnya mengurusi bahasa manusia, dalam hal ini mengurusi pemahaman dan produksi bahasa (Dardjowijojo, 1986:146) Dengan demikian, strukturb anatomis ini menyokong sepenuhnya klaim TPB Model Nativis LAD tentang adanya LAD di dalam struktur kejiwaan manusia. 
Secara konseptual LAD ini didefinisikan sebagai struktur kejiwaan yang mengurusi bahasa yang secara kodrati atau bawaan terdapat di dalam benak setiap manusia sejak lahirnya; jadi LAD dimiliki oleh setiap manusia (Chomsky, 1965:31-32). LAD ini bersifat umum, bekerja secara analistis logis, dan beroperasi secara sadar (Saryono, 1987;234). Di dalam LAD ini terdapat dua komponen pengolah masukan data linguistik, yaitu (1) prosedur-prosedur untuk mengoperasikan korpus, misalnya mengadakan analisa distribusional atau menggunakan 'kaidah-kaidah penyimpulan' (inference rules) untuk mendapatkan transformasi-transformasi tertentu, dan (2) informasi linguistik, misalnya informasi bahwa semua kalimat termasuk frase nomina dan verba.

Secara pasti dan konkrit isi LAD tidak dapat diketahui. Yang jelas dengan komponen-komponen tersebut LAD mampu memproses masukan data linguistik yang diterimanya dengan jalan internalisasi. Dengan kata lain LAD berkemampuan menginternalisasikan masukan data linguistik dan membuat kaidah-kaidah tatabahasa (Chomsky, 1965:31-32). MacNeil (1966) menambahkan bahwa LAD memiliki kemampuan untuk (1) memilah-milahkan antara suara manusia dengan suara yang lain, (2) mengorganisaikan kejadian-kejadian linguistik menjadi kelas-kelas tertentu yang secara "sambil jalan" klasifikasi ini disempurnakan, (3) mengatur masukan data linguistik yang sudah diklasifikasikan pada butir (2) menjadi kaidah-kaidah bahasa, dan (4) mengadakan penilaian yang terus-menerus dalam rangka membuat sistem bahasa yang paling sederhana. Jadi, LAD memiliki kemampuan mengolah masukan data linguistik yang diterimanya menjadi kompetensi gramatikal (Baradja, 1986:8).

Di dalam benak manusia yang sedang belajar bahasa LAD bekerja mengolah masukan-masukan data linguistik dengan jalan membentuk hipotesis-hipotesis tentang sistem bahasa dan kaidahkaidah bahasa yang dipelajari. Si belajar berupaya mengoperasikan LAD-nya untuk membentuk hipotesis tentang kaidah bahasa yang dipelajari dan memperbaikinya. Hal ini dikerjakan secara bawah sadar. Hipotesi yang telah ditetapkan secara bawah sadar kemudian diuji 
dalam pemakaian bahasa sehari-hari oleh si belajar. Hal ini mengakibatkan berubahnya hipotesis si belajar tentang kaidah bahasa yang dipelajarinya dan disesuaikannya hipotesis itu secara teratur. Hipotesis yang salah atau keliru diperbaiki sampai sempurna dan hipotesis yang benar menjadi pengetahuan tentang sistem kaidah bahasa yang dipelajari. Dengan jalan demikian lah si belajar mengembangkan sistem belajarnya menuju sistem kaidah yang sempurna seperti dituturkan oleh penutur dewasa, si belajar mengembangkan sistem belajarnya secara teratur dan sistematis (Chomsky, 1965:25-32)

Berkaitan dengan hipotesis tentang sistem bahasa yang dipelajari tersebut diatas perlu dikemukakan dua hal. Pertama, LAD tidak berisi bahasa tertentu sebab LAD tidak berhubungan secara langsung dengan bahasa tertentu. Oleh karena itu, bahasa apakah yang di hipotesis oleh si belajar bergantung pada bahasa apakah yang menjadi masukannya, bahasa apakah yang menjadi data linguistiknya. Kedua, LAD pada dasarnya "mesin" pengelolahan bahasa yang terdapat pada struktur kejiwaan manusia sehingga selalu siap menerima data masukan linguistik apapun tanpa pemilihan tertentu. Bahasa apapun bisa diolahnya. Tidak ada bahasa tertentu yang diistimewakan oleh LAD untuk di hipotesiskan bahasa apapun yang menjadi masukannya pasti di hipotesiskan. (Crystal, 1979:36).

Adanya dua hal tersebut diatas membuat sibelajar bersikap bertindak lentur. Si belajar dapat memperoleh belajar bahasa apapun dengan baik meskipun data linguistik yang masuk dalam data LAD berbeda-beda. Misalnya, anak-anak dapat memperoleh bahasa Inggris sebaik mereka memperoleh bahasa Cina karena mesin pengolahnya sama, yaitu LAD. Demikian juga anak-anak yang memproleh bahasa Indonesia dapat dengan baik pula memperoleh bahasa Inggris ( jika mengaktifkan si belajar dalam pemerolehan bahasa) sebab LAD tidak berisi bahasa tertentu (Baradja, 1986:7).

Berdasarkan paparan tentang konsep dan prinsip kerja LAD tersebut diatas dapat dipahami bagaimana pemerolehan LAD dapat 
berlangsung Menurut TPB Model Nativis LAD. Menurut TPB Model Nativis LAD terdapat 3 komponen mekanisme perolehan bahasa yaitu masukan, pengolah, dan keluaran. Masukan berisi data linguistik primer yang berupa bahasa tertentu. Misalnya bahasa Indonesia. Pengolah berisi LAD dengan prinsip-prinsip kerja sebagaimana dikemukakan diatas. Keluaran berisi kompetensi gramatikal bahasa yang dipelajari oleh si belajar . Mekanisme kerja ketiga komponen kerja sebagai berikut:

MASUKAN

PENGOLAH

KELUARAN

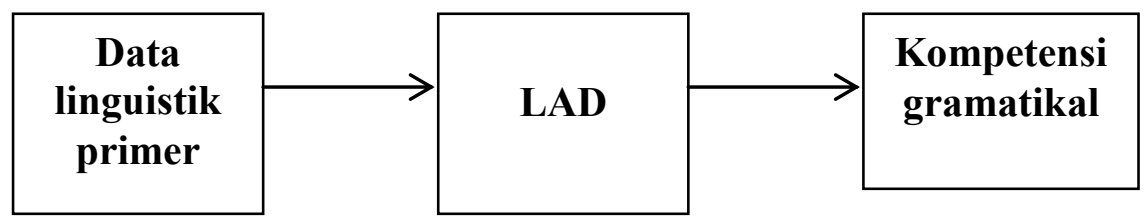

Perlu ditambahkkan, data linguistik primer berupa ujaran orang dewasa dan kompetensi gramatikal berupa tata bahasa yang pada akhirnya terwujud dalam ujaran si belajar. (Chomsky, 1972:118)

Cara kerja LAD juga dapat digambarkan sebagai berikut (Bambang, 1995:276) :

INPUT

LAD

OUTPUT

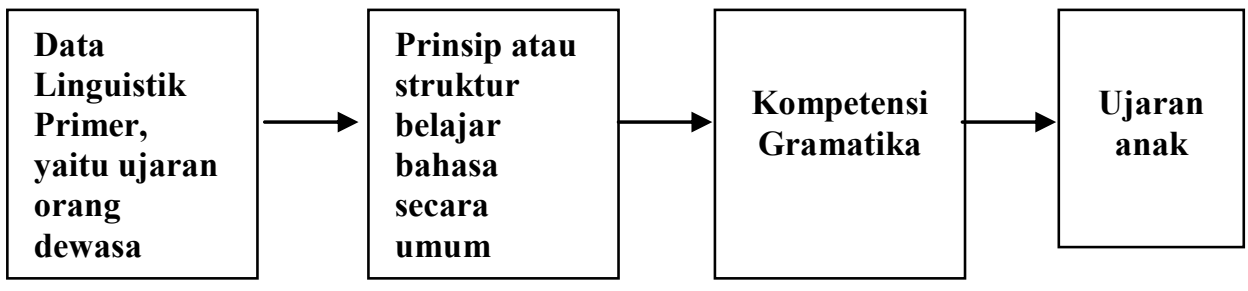


Pola ujaran dalam lingkungan anak merupakan data linguistik primer yang memberi input (masukan) kepada anak. Data itu diolah oleh LAD dengan menggunakan hipotesis yang diturunkan mengenai gramatika bahasa - kalimat apa ujaran itu, siapa dan dimana orang yang menyampaikan ujaran itu, dan seterusnya. Salah satu hasil pengolahan itu ialah tercapainya kesimpulan bahwa subyek mendahului verba. Dengan cara seperti itu anak mengumpulkan informasi-informasi spesifik mengenai struktur gramatika bahasnya sendiri dengan menggunakan prinsip umum atau universal itu. Pemerolehan kompetensi gramatika itu muncul dalam produksi kalimatnya yang sesuai dengan ujaran orang dewasa. Dengan kata lain, akhir ujaran yang dihasilkan akan menyamai input yang dia terima.

Mekanisme kerja tersebut menunjukkan bahwa proses pemerolehan sangat tergantung pada LAD. LAD adalah satu-satunya komponen yang terlibat di dalam proses pemerolehan bahasa. tidak ada komponen lain (baik komponen kognitif maupun afektif) selain LAD yang beroperasi sewaktu proses pemerolehan bahasa berlangsung. Hal ini mengimplikasikan bahwa proses pemerolehan bahasa mengikuti strategi umum tanpa dipengaruhi oleh faktor-faktor lain. Dalam hubungan inilah kemudian Chomsky mencetuskan hipotesis universal dan adanya tata bahasa universal. Hipotesis universal meyakini bahwa faktor linguistik lebih menentukan proses pemerolehan daripada faktorfaktor kognitif umum. Sedangkan tata bahasa universal merupakan sifat yang sudah melekat dalam pikiran manusia yang terdiri atas seperangkat prinsip umum yang diterapkan pada semua bahasa daripada seperangkat kaidah khusus. Jadi TPB Model Nativis LAD berkeyakinan bahwa proses pemerolehan bahasa lebih dikendalikan oleh strategi umum yang bersifat linguistis dan khas bahasa yang oleh Chomsky disebut tata bahasa universal.

Implikasi lebih lanjut pengakuan adanya tata bahasa universal sewaktu LAD beroperasi ialah bahwa pemerolehan bahasa mengikuti tahapan-tahapan dan atau urutan-urutan yang teratur dan sistematis. 
Seseorang yang belajar bahasa akan memperoleh bahasa yang dipelajarinya secara berangsur-angsur sesuai dengan strategi umum pemerolehan bahasa yang terdapat di dalam LAD.

\section{Kritik-Kritik terhadap TPB Model Nativis LAD}

Meskipun banyak penelitian mendukung pandangan dasar TPB Model Nativis LAD, tetapi berbagai kritik juga sering dilontarkan. Kritik-kritik terhadap model ini terpusat pada konsep LAD yang dicetuskan Chomsky. Brown (1980: 22-23) menyatakan bahwa proposisi LAD terlalu filosofis dan tidak memiliki landasan yang kuat. Menurut Brown proposisi LAD sama dengan proposisi adanya Tuhan yang menciptakan manusia. Kita tidak tahu pasti bagaimana manusia diciptakan sehingga kita mengusulkan adanya entitas sebagai pencipta manusia. Demikian juga hakikatnya adanya LAD, kita sebenarnya tidak mengetahui secara pasti bagaimana anak mampu mengelolah bahasa sehingga dia mampu memperoleh bahasa dengan baik. Paivio dan Berg (1981:238-241) mempertanyakan asumsi atau pandangan dasar TPB Model Nativis LAD itu mengenai kekodratian kemampuan dan kememadaian model linguistik generatif transformasi sebagai pendekatan untuk mengkaji perkembangan bahasa. Mereka mengemukakan bahwa walaupun ujaran-ujaran anak-anak dapat dibangkitkan memlalui kaidah struktur dasar tanpa transformasi, akan tetapi kemampuan itu kodrati atau bawaan. Selain itu, dapatkah setiap konstruksi diperoleh melalui pengalaman. Beberapa bukti menunjukkan demikian. Hal ini menunjukkan kelemahan TPB Model Nativis LAD yang menyatakan bahwa peranan lingkungan kecil sekali dalam pemerolehan bahasa.

Kritik lain mempertanyakan mekanisme kerja LAD yang bilingual. TPB Model Nativis LAD tidak menyinggung persoalan ini dalam paradigma teorinya. LAD hanya digunakan dalam pemerolehan bahasa anak-anak yang berada di lingkungan satu bahasa saja. Oleh karena itu , Monks (1987:134) menyatakan bahwa LAD tidak dapat diuji 
secara empiris, LAD hanyalah spekulasi rasionalis-logis yang hanya hidup di dalam pikiran manusia.

\section{Analisis Kritis terhadap TPB Model Nativis LAD}

Beberapa kritik yang dikemukakan di atas dapat dimengerti sebab LAD memang sangat filosofis, rasionalis, dan sulit sekali dibuktikan secara empiris. Chomsky sendiri tidak pernah memberi bukti secara empiris melalui penelitian khusus. Meskipun demikian, tidak berarti LAD tidak dapat dibuktikan secara empiris. Kemungkinan LAD dapat dibuktikan secara empiris cukup besar. Bahkan adanya LAD itu sendiri secara rasionalis-logis dapat diterima sebab tidak mungkin manusia dapat memperoleh bahasa atau belajar bahasa tanpa mempunyai alat khusus untuk itu. Yang tidak dapat diterima ialah penggunaan LAD sebagai satu-satunya unsur yang menentukan pemerolehan bahasa.

Pandangan TPB Model Nativis LAD bahwa LAD sebagai satusatunya faktor yang menentukan pemerolehan bahasa anak-anak sebenarnya tidak berbeda dengan pandangan TPB Model Pongondisian Operan tentang lingkungan sebagai satu-satunya yang menentukan pemerolehan bahasa. TPB Model Nativis LAD yang menafikan peranan lingkungan dalam pemerolehan bahasa seperti pandangan TPB Model Pongondisian Operan yang menafikan peranan faktor kejiwaan dalam pemerolehan bahasa. sebab itu, TPB Model Nativis LAD tentang keserba bisaan dan keampuhan LAD sesungguhnya terlalu menyederhanakan persoalan.

Sehubungan dengan itu, dapat diajukan beberapa pertanyaan: apakah faktor-faktor kejiwaan seperti afeksi, bakat kepribadian, dan pengalaman-pengalaman si belajar tidak berpengaruh sama sekali dalam pemerolehan bahasa?, apakah faktor lingkungan seperti situasi, tempat tinggal, dan linkungan bahasa tidak berperanan dalam pemerolehan bahasa?, apakah semua aspek pemerolehan bahasa hanya ditentukan oleh LAD? Jika jawabannya tidak berarti TPB Model Nativis LAD telah mencabut manusia selaku si belajar dari dunia empiris dan 
menempatkan manusia dalam dunia rasionalis/pemikiran saja. Nampaknya Chomsky tidak memperhitungkan persoalan-persoalan tersebut di atas.

Meskipun mendapat berbagai kritik dan sanggahan, TPB Model Nativis LAD patut dihargai. Penghargaan terhadap model ini dapat berupa pembelaan dan pengakuan perannya. Baradja (1986) menghargai teori ini dengan jalan membela teori dari kritik yang disampaikan oleh Brown. Ia berpendapat bahwa kritik yang dilontarkan Brown mengenai LAD kurang dilandasi oleh pandangan filosofis yang benar. Menurut Baradja, sebuah teori merupakan suatu proposisi yang menurut hakikatnya filosofis. Kekuatan suatu teori tidak terletak pada bisa tidaknya teori itu diamati, tetapi terletak pada kecocokan eksplanatori dengan fakta. Atas dasar hal ini menurut Baradja LAD dapat diukur kebenarannya.

Selanjutnya Baradja mengemukakan bahwa teori yang memiliki kekuatan eksplanatori lebih besar berarti lebih bermanfaat. Dibandingkan dengan TPB Model Pongondisian Operan TPB Model Nativis LAD mempunyai kekuatan eksplanatori yang lebih baik. Hal ini sudah dibuktikan oleh TPB Model Nativis LAD. Teori ini sudah demikian banyak melahirkan pemikiran-pemikiran dan pengkajianpengkajian pemerolehan bahasa baik B1 maupun B2. Diantaranya ialah sumbangan tentang teori makna, semestaan bahasa, dan pengkajian pemerolehan bahasa pertama (1968:9).

TPB Model Nativis LAD harus dihargai juga karena peranannya demikian besar dalam mengubah paradigma pemikiran dan penelitian pemerolehan bahasa. Oleh karena itu (Samsuri:1987:44-45) menjajarkan Chomsky dengan Copernicus. Hal ini berarti pekerjaan Chomsky dalam mengembangkan TPB Model Nativis LAD setara dengan pekerjaan Copernicus dalam mengubah pandangan manusia tentang tata surya yang geosentris menuju heliosentris. Jika memang demikian kualitas pekerjaan yang telah dilakukan oleh Chomsky, maka TPB Model Nativis LAD merupakan tonggak besar yang menandai paradigma berpikir dan 
mengkaji paralinguis atau ahli pengajaran bahasa tentang pemerolehan bahasa.

\section{Penutup}

Patut dihargai, bahwa peranan TPB Model Nativis LAD dalam memberikan ilham kepada para linguis dan ahli pengajaran kedua untuk meneliti perolehan B2. Model ini telah mendorong dilakukannya penelitian-penelitian pemerolehan B2 secara sistematis dan seksama, baik penelitian tentang strategi pemerolehan, kesilapan dalam pemerolehan, laju perkembangan maupun urutan pemerolehan dan tingkat kemahiran. Yang paling penting ialah bahwa adanya TPB Model Nativis LAD dan penelitian-penelitian pemerolehan B2 yang diilhami model teori itu telah mendorong lahirnya model TPB baru yang berkenaan dengan pemerolehan B2. Dua diantaranya ialah TPB Model Monitor dan TPB Model Konstruksi Kreatif. Kedua TPB ini sangat diwarnai oleh konsep LAD. $\nabla$ 


\section{DAFTAR PUSTAKA}

Bambang, Yudi Cahyono. 1995. Kristal-Kristal Ilmu Bahasa. Surabaya: Airlangga University Press.

Baradja, M.F. 1986. Pemerolehan Bahasa Pertama. Buku Pegangan Pengajaran Bahasa. Malang: Fakultas Pasca Sarjana IKIP Malang.

Chomsky, Noam. 1959. A Review of B.F. Skinner Verbal Behavior dalam language, 35. No.1.

-------. 1965. Aspect of The Theory of Syntax. Cambrige: Massachusetts: MIT Press.

1968. Language and Mind. New York: Harcourt. Brace and World Inc.

1975. Reflection on Language. New York: Pantheon Books.

1977. Language and Responsibility. New York Pantheon Books.

Crystal, 1979. Child Language, Learning And Linguistics. Victoris: Edward Arnold.

Dardjowijojo, Soenjono.1986. Dasar-dasar Neurovisiologis dalam Pengajaran Bahasa. Jakarta: Penerbit ARCAN.

Monks, F.J. 1987. Psikologi Perkembangan. Yogyakarta: UGM Press.

Paivio dan Berg .1981. Psychology of Language. New Jersey: Prentice Hall. Inc.

Pardja, Juhaya S. 1987. Aliran-aliran Filsafat dari Rasionalisme hingga Sekularisme. Bandung: Alva Gracia.

Samsuri, 1973. Memilih Kerangka Acuan Tatabahasa Indonesia. Malang: BIRO I IKIP Malang.

Saryono, Djoko. 1987. Urutan Pemerolehan Bahasa Kedua dan Implikasinya dalam Pengajaran Bahasa Kedua. Kapita Selekta Kajian Bahasa dan Pengajarannya. Malang: JPBS FPBS IKIP Malang.

Tarigan, Henry Guntur. 1985. Psikolinguistik. Bandung: Penerbit Angkasa. 